\title{
A CUSP CATASTROPHE MODEL FOR DEVELOPING MARKETING STRATEGIES FOR ONLINE ART AUCTION
}

\author{
Yong Xiang \\ Peking University \\ No. 5, Yiheyuan Road Haidian District, Beijing, P.R. 100871, China \\ xiangy@pku.edu.cn \\ Yu-Kai Huang \\ Nanhua University \\ No. 55, Sec. 1, Nanhua Rd., Dalin Township, Chiayi County 62249, \\ Taiwan \\ osilo.huang@gmail.com \\ Kwok-Leung Li \\ Paris 8 University \\ No. 971, King's Road, Huang Kung \\ xuokk@hotmail.com
}

\begin{abstract}
Online auction is one of the successful business models in electronic commerce. In recent years, online auction has once again become an important part in many people's lives, setting new records in transaction amounts and bringing huge profits to the owners of auction websites. Customer satisfaction has become an important issue for online auction. The main purpose of this study is to explore the relationship between e-service quality and satisfaction by using a catastrophe model. The latent variables and manifest variables are defined in the Structural Equation Model (SEM). The catastrophe model was used to developing marketing. The empirical results demonstrated that design is the key factors to impact on consumers to choose the online art auction web site.
\end{abstract}

Keywords: Online Auction Art Website, Cusp Catastrophe Model, GEMCAT 


\section{INTRODUCTION}

Digital technology has provided a new paradigm of our society and changed our lives interaction with the Internet ${ }^{1}$. As an efficient and flexible sales channel, companies can use auction sites to liquidate unwanted inventory, as well as to assist in pricing new products, acquiring new markets for low-margin items, and reaching markets that would be too costly using traditional distribution methods. Electronic stores emerged as a popular retail channel and became a significant destination for online shopping. The online auction business model is one in which participants bid for products and services over the Internet. The functionality of buying and selling in an auction format is made possible through auction software which regulates the various processes involved. Customer satisfaction is fundamental to business. The quality of service performance is an important key factor to create customer satisfaction. In the past decade, there has been much research published about the theoretical domain of service quality in a business-to-business context. However, there is a lack of research on e-service quality for the online auction in consumer-to-consumer environment.

\section{METHOD}

The catastrophe structure most commonly has been applied the cusp model $^{2}$. Each catastrophe model can be formalized by potential or gradient structures. A potential function $\mathrm{F}(\mathrm{x}, \mathrm{c})$ is a function of both the system state $\mathrm{x}$ and the control parameter(s) $c$. The Cusp Catastrophe Model (CCM) consists of one behavior variable and only two control variables. The potential is represented by Eq. (1), the equilibrium of Eq. (1) is three-dimensional.

$$
F(u, v, x)=-\frac{1}{4} x^{4}+\frac{1}{2} u x^{2}+v x(1)
$$

Where the state variable $\mathrm{x}$ is controllability, and $\mathrm{u}$ and $\mathrm{v}$ are environmental control parameters. As a stable equilibrium state $\mathrm{x}$ for this potential gives relative value $\mathrm{x}$ of a function $\mathrm{F}(\mathrm{u}, \mathrm{v}, \mathrm{x})$, a set of point $(\mathrm{u}, \mathrm{v}, \mathrm{x})$ is defined as Eq. (2),

$$
\frac{\partial F}{\partial x}=-x^{3}+u x+v=0 ; M_{F}:\left\{(u, v, x) \mid-x^{3}+u x+v=0\right\}
$$


Where MF is said to be cusp catastrophe manifold. The values of $\mathrm{x}$ in correspondence to which attains a local maximum or minimum satisfies the condition as Eq. (3),

$$
3 x^{2}+u=0
$$

Eliminating $x$ from Eq. (2) and Eq. (3), the bifurcation set is expressed by Eq. (4). In Zeeman's terminology $u$ is a splitting factor and $\mathrm{v}$ is normal factor.

$$
4 u^{3}=27 v^{2}
$$

A switch in topology takes place at the values of $u$ and $v$ satisfying Eq. (4), which constitute the catastrophe set. In the equation Eq. (3) $x$ is the state variable, and $u, v$ are control parameters. The parameter u determines whether the system has one or can have two stable equilibrium. When $u>0$ only one stable equilibrium can exit whatever the value of $v$. When $u<0$ it depends upon the value of $\mathrm{v}$ whether the system has a single low level of stable equilibrium, or a low level and a high level equilibrium, or a single high level of equilibrium. According to the different variable sets, three different cases can be defined.

Case 1: There is one stable equilibrium point;

Case 2: There are two stable and one unstable equilibrium point;

Case 3: There is one stable equilibrium point, and one at which an instantaneous jump in the state variable occurrence.

Currently, three different approaches are considered the most appropriate for estimating catastrophe models. The first is by $\mathrm{Cobb}^{3}$, the second is by Guastelo ${ }^{4}$ and the third is GEMCAT, developed by Oliva et al. ${ }^{5}$. GEMCAT, in contrast, is a confirmatory multivariate analytical procedure. These three methods are different, each having its own advantages and disadvantages. Cobb's procedure is classified as an exploratory statistical method in which researchers cannot indicate a priori, or which measured variables relate to which independent variable ${ }^{6}$. Estimation of catastrophe models is difficult because of nonlinear dynamic characteristics. Several cusp-fitting procedures have been proposed, but none is completely satisfactory. GEMCAT approaches have been successfully applied in a number of different organizational research contexts ${ }^{7,8}$. Oliva et al.'s GEMCAT approach allows all variables in a catastrophe to be latent 
composites $^{6}$. To accomplish this, the variable $\mathrm{X}, \mathrm{Y}$, and $\mathrm{Z}$ in the canonical cusp is presented by Eq. $(5)^{\mathrm{h}}$,

$$
f\left(X_{t}^{*}, Y_{t}^{*}, Z_{t}^{*}\right)=-\frac{1}{4} Z_{t}^{* 4}+X_{t}^{*} Z_{t}^{*}+\frac{1}{2} Y_{t}^{*} Z_{t}^{* 2}
$$

The equation (5) can be redefined as these three "latent" unobservable constructs which can thus accommodate univariate or multivariate measurements for each type of variable. From equation Eq. (5) the estimating goal is to minimize Eq. (6) ${ }^{\mathrm{i}}$

$$
\operatorname{Min}_{\alpha i, \beta j, \gamma k} \Phi=\left\|e_{t}^{2}\right\|=\sum_{t=1}^{T}\left[-Z_{t}^{*^{3}}+X_{t}^{*}+Y_{t}^{*} Z_{t}^{*}\right]^{2}
$$

That is, for a given empirical data on various specified dependent, splitting, and normal variables, one wishes to estimate the impact coefficients that define their respective latent variables, which make $\Phi$ as close to zero as possible. Minimizing $\Phi$ is equivalent to find the best fitting cusp catastrophe surface to the empirical data.

\section{ANALYSIS AND RESULTS}

\subsection{Data}

There are two major online auction websites in Taiwan: Yahoo.com and Ruten.com. We developed the e-Service quality and select Yahoo.com and Ruten.com for our study case. In our study, a Web-based survey was employed. In total, 295 cases were gathered in June 2010. More than 67\% of the respondents were female. More than $70 \%$ of the respondents were $19-40$ years old, while fewer than $6 \%$ of the respondents were over 51 years old. Most respondents $(65 \%)$ were single, and most respondents $(70 \%)$ reported having a bachelors degree. Furthermore, more than half of the respondents were students or employees of a company, and more than $53 \%$ of the respondents reported living in northern Taiwan.

${ }^{\mathrm{h}_{i}}=1 \ldots I$ dependent variables; $j=1 \ldots J$ "splitting" independent variables; $k=1 \ldots K$ "normal" independent vatiables; $t=1 \ldots T$ observations; $Z_{i t}=$ the value of the $i$-th dependent variable on observation $\mathrm{t} ; \mathrm{Y}_{j t}=$ the value of the $j$-th splitting independent variable on observation $\mathrm{t} ; \mathrm{X}_{k t}=$ the value of the $k$-th normal independent variable on observation $\mathrm{t}$.

${ }^{\mathrm{i}} Z_{t}^{*}=\sum_{i=1}^{I} \alpha_{i} Z_{i t} ; \quad Y_{t}^{*}=\sum_{j=1}^{{ }_{j=1}} \beta_{j} Y_{j t} ; \quad X_{t}^{*}=\sum_{k=1}^{K} \gamma_{k} X_{k t} ;$ independent variable in Our operationalizations of the dependent and independent indicator are measure is as follows:

State variable : Satisfaction: $\mathrm{x}^{*}=\mathrm{f}\left(\mathrm{x}_{1}, \mathrm{x}_{2}, \mathrm{x}_{3}\right)$

Normal factor : E-Service quality : $\mathrm{v}^{*}=\mathrm{f}\left(\mathrm{v}_{1}, \mathrm{v}_{2}, \mathrm{v}_{3}, \mathrm{v}_{4}, \mathrm{v}_{5}, \mathrm{v}_{6}, \mathrm{v}_{7}, \mathrm{v}_{8}, \mathrm{v}_{9}, \mathrm{v}_{10}, \mathrm{v}_{11}, \mathrm{v}_{12}, \mathrm{v}_{13}, \mathrm{v}_{14}\right.$, $\mathrm{v}_{15}, \mathrm{v}_{16}$ )

Splitting factor : Switching barrier : $\mathrm{u}^{*}=\mathrm{f}\left(\mathrm{u}_{1}, \mathrm{u}_{2}, \mathrm{u}_{3}\right)$ 


\subsection{Catastrophe Modeling and Estimating}

The control variables in the model are the normal variable $v$ is defined in terms of "relative logistics service quality" ( $v_{k}$ with weight $\left.\gamma_{k}\right)$, and the splitting variable $\mathrm{u}$ uses the "switching cost" indicator $\left(u_{j}\right.$ with weight $\beta_{j}$ ), whereas the dependent variable $\mathrm{x}$ is defined in terms of relative loyalty $\left(x_{i}\right.$ with weight $\alpha_{i}$ ). After transforming all variables to $\mathrm{z}$-scores (i.e., $\mathrm{M}=0$, $\mathrm{SD}=1$ ), GENCAT II was employed to fit the hypothesized cusp catastrophe model. Data were fitted using GEMCAT II version 1.3, substitution of these weights into Eq. (5). Figure 1 shows the relationships between control variables and dependent variable. Consider two points at the far edge of the surface (low switching barrier; see Fig. 2), they represent satisfaction with the same value of e-service quality, but slightly different values of switching barrier. If the value of e-service quality increases, the points move forward toward the front of the surface, tracing parallel paths. The figure also shows discontinuous change when a point moves from the left to the right of the surface. At the far edge of the surface, a point can pass smoothly from left to right. But if point is at the front of the surface (high switching barrier), a discontinuous jump will occur at the pleat. At the back of the surface where the switching barrier is small; the satisfaction is dependent only on its e-service quality and increases continuously with it. Increases switching barrier its magnitude lead to a progressively larger divergence between the top and the bottom of the response surface.

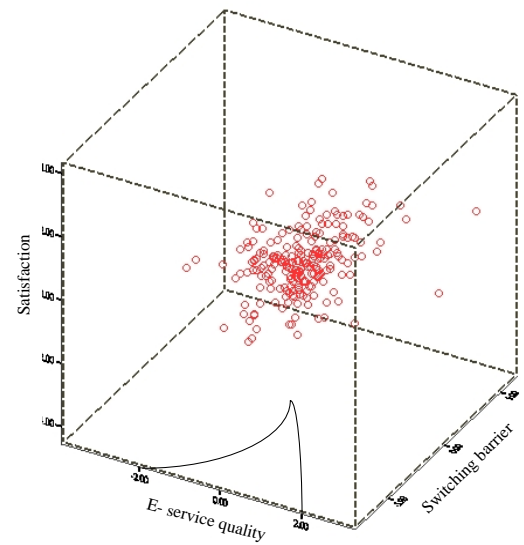

Figure 1. A graphical illustration of cusp catastrophe model 


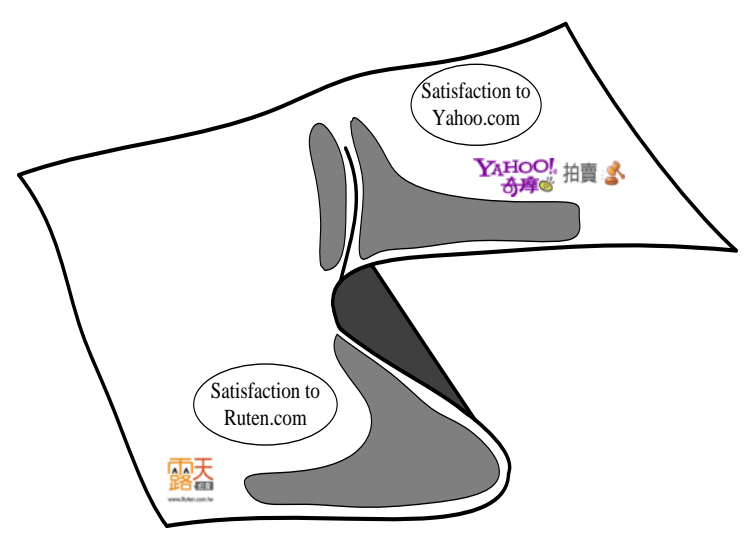

Figure 2. Cusp catastrophe model of online art auction website

\subsection{Implications for Marketing Strategy}

Moving from the more tactical issues discussed in the illustration to more strategic issues pertaining to service strategy in general, our research indicates that, depending on switching barrier, the relation between e-service quality and satisfaction can be nonlinear, at least for some facets of service. This finding has important implications for satisfaction strategies and decisions on how to deploy a limited budget across different opportunities to enhance service, given that competitors are making similar decisions. The cusp catastrophe model has five important features. We develop our four different types of satisfaction strategies via the catastrophe characteristic and the hysteresis characteristic in this section as shown in Figure 3. We use Ruten.com as an example and develop satisfaction strategies via the cusp catastrophe model. Clustering analysis to identify convertible consumers is the first step of developing satisfaction strategy. As shown in Figure 3, it is difficult for any strategies to change a consumer if he or she is very satisfied with Yahoo.com or the switching barrier is very high. Idea-convertible consumers must have medium switching barriers and there should be a difference in service quality between Yahoo.com and Ruten.com.

According to our analysis above, switching barrier and e-service quality are the two main factors influencing satisfaction. That is, when perceived switching barriers are low, dissatisfied consumers should be more likely to defect than satisfied customers, because perceived switching benefits outweigh perceived switching barriers. Simply speaking, when perceived switching barriers are high, customers may remain in spite of their dissatisfaction, owing to the perceived switching benefits. Thus, the relationship between customer satisfaction and satisfaction is stronger for 
customers with high switching barriers than for those with low switching barriers.

E-Service quality and switching barrier are the control variables in our cusp catastrophe model. Switching barrier is the customer's perception of loss in terms of time, money, and psychological costs when switching. Many studies argued that it is defined as perceived risks when switching service providers, and the potential perceived losses are of financial, performance-related, social, psychological, and safety-related nature. When a customer switches to another service provider, some uncertainty exists that a new supplier might not perform the core service at a level equal to, or better than, the current supplier. Clearly, switching barriers seem to be an important element when a consumer is deciding whether to switch to a service provider. Because the indicator u3 (switching barrier concerning the distance) has the greatest impact on satisfaction among the different indicators of switching barrier, one of these satisfaction strategies will be related to indicator u3. From the short-term point of view, indicator v4 (marketing program) is the most important factor among the four indicators of service quality of the control variables $u i$. Sales promotions can encourage consumers to either buy larger quantities of the promoted product or buy that product at an earlier time. By definition, the objective of sales promotions is to offer a direct incentive that affects consumers to accelerate their purchase.

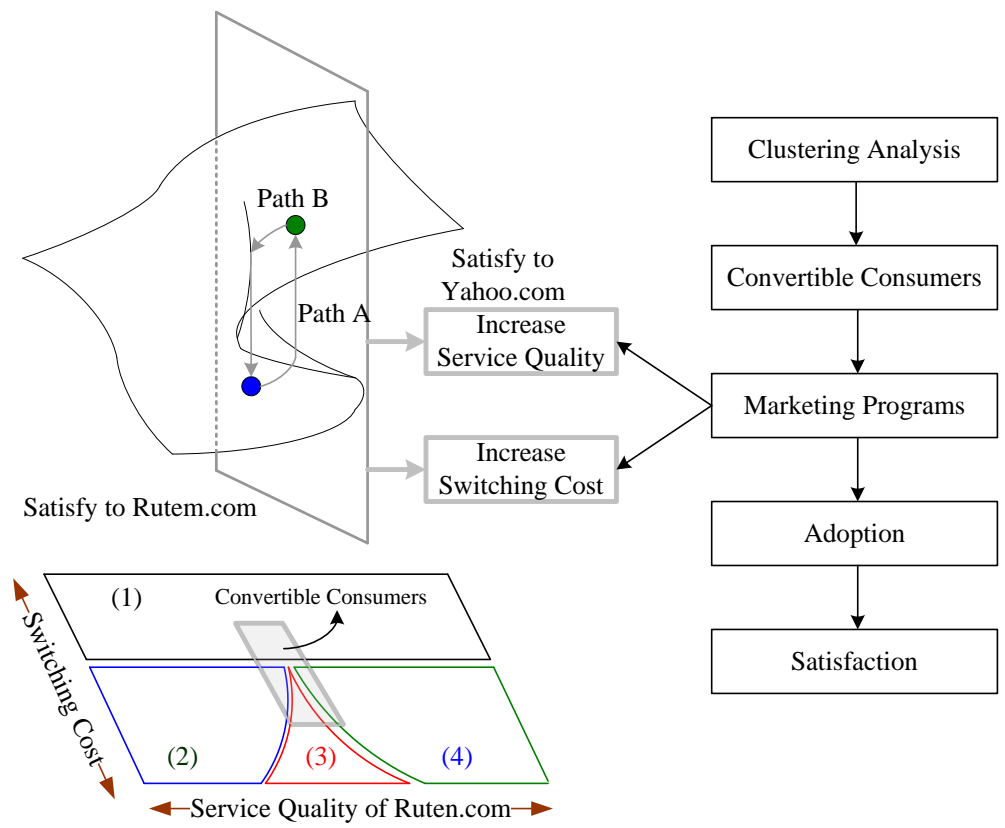

Figure 3. Developing satisfaction strategy via catastrophe model 


\section{CONCULSION}

A cusp model of consumer behavior was developed to describe the effects of both e-service quality and switching barrier on satisfaction. Our intention in this paper has been to describe a way in which a cusp catastrophe model has been used to develop an online art auction service marketing strategy for an established brand in the online art auction market. It had been expected that a catastrophe approach to discontinuous behavior has clearly abundant implications. Based on the findings of satisfaction in the application of cusp catastrophe theory, the cusp catastrophe model is an appropriate model to know the process of satisfaction. The managerial implications and suggestions are as follows:

- Online art auction managers must focus on e-service quality to heighten customer satisfaction. At the same time, efforts to raise the switching barrier must build a long-term relationship with customers by further investing in customer relationship management.

- Online art auction manager must increase the switching barrier in order to increase its occupation rate of market.

\section{REFERENCES}

[1] V.A. Zeithaml, A. Parasuraman, and A. Malhotra, Service quality delivery through web sites: A critical review of extant knowledge. Journal of the Academy of Marketing Science, 30(4), p362-375, 2002. http://dx.doi.org/10.1177/009207002236911.

[2] G. Gresov, H.A. Haveman, and T.A. Oliva, Organizational design, inertia and the dynamics of competitive response. Organization Science, 4(2), p 181-208, 1993. http://dx.doi.org/10.1287/orsc.4.2.181.

[3] L. Cobb, Stochastic catastrophe models and multimodal distributions. Behavioral Science, 23(4), p360-374, 1978. http://dx.doi.org/10.1002/bs.3830230407.

[4] S.J. Guastello, A butterfly catastrophe model of motivation in organizations: Academic performance. Journal of Applied Psychology, 72(1), p165-182, 1987. http://dx.doi.org/10.1037//0021-9010.72.1.165.

[5] T.A. Olvia, W.S. Desarbo, D.L. Day, and K. Jedidi, GEMCAT: A GEneral multivariate methodology for estimating CATastrophe models. Behavior Science, 32(2), p121-137, 1987. http://dx.doi.org/10.1002/bs.3830320205.

[6] T.A. Oliva, R.L. Oliver, and I.C. MacMillian, A catastrophe model for developing service satisfaction strategies. Journal of Marketing, 56(3), p83-95, 1992. http://dx.doi.org/10.2307/1252298. 
[7] R.G. Kauffman, and T.A. Oliva, Multivariate catastrophe model estimation: Method and application. Academy of Management Journal, 37(1), p206-221, 1994. http://dx.doi.org/10.2307/256778.

[8] L. Lange, S. McDade, and T.A. Oliva, Technological choice and network externalities: A catastrophe model analysis of firm software adoption for competing operating systems. Structural Change and Economic Dynamics, 12(1), p29-57, 2001. http://dx.doi.org/10.1016/S0954-349X(00)00028-X.

\section{APPENDIX}

The measure scale about state variable and control variable is as the following:

1. State variable (satisfaction: $\mathrm{X}_{1} \sim \mathrm{X}_{3}$ ): "I will recommend this online art auctionwebsites' service to my friends,", "If I want to choose an online art website, I will choose this one," "Compared to other online art auction website, I prefer this one."

2. Normal factor (e-service quality: $\mathrm{v}_{1} \sim \mathrm{v}_{3}$ ): "I can find the products that I need by using search engine easily", "The site records all the products I have ever browsed, and it allows me to browse them again conveniently,","The hyperlinks make it convenient to browse the products that interest me," "The site is simple to use," "There are special measures for protecting information about my on-line transaction," "Advertisements will not be mailed to me without my permission", "The site has passed a security review and has the secure symbols," "The site is attractively designed and is visually pleasing," "The display of objectives and graphics is appealing," "The text and graphics are clear and easy to understand," "The information about products is accurate," "The site provides information about best-selling products," "The information about products is sufficient," "The site loads its pages quickly," "It provides the functions for interaction," "It gives me numerous options of merchandise other than products."

3. Splitting factor (switching barrier: $\mathrm{u}_{1} \sim \mathrm{u}_{3}$ ): "I am used to choosing the same online art auction website," "If I choose another online auction website, I think it is not convenient for me," "If I choose another online auction website, I will lose some premiums." 
